\title{
An assessment of antibacterial activity of three pulp capping materials on Enterococcus faecalis by a direct contact test: An in vitro study
}

\author{
Mine Koruyucu ${ }^{1}$, Nursen Topcuoglu ${ }^{2}$, E. Bahar Tuna ${ }^{1}$, Sevda Ozel ${ }^{3}$, Koray Gencay ${ }^{1}$, \\ Guven Kulekci' ${ }^{2}$, Figen Seymen ${ }^{1}$
}

Correspondence: Dr. Mine Koruyucu

Email: minekoruyucu@gmail.com

\author{
'Department of Pedodontics, Faculty of Dentistry, \\ Istanbul University, Istanbul, Turkiye, \\ 2Department of Microbiology, Faculty of Dentistry, \\ Istanbul University, Istanbul, Turkiye, \\ ${ }^{3}$ Department of Biostatistics and Medical Informatics, \\ Faculty of Medicine, Istanbul University, Istanbul, \\ Turkiye
}

\section{ABSTRACT}

Objective: The aim of this in vitro study was to evaluate antimicrobial activities of three different pulp capping materials; Biodentine, mineral trioxide aggregate (MTA) Angelus, and Dycal against Enterococcus faecalis and their durability with time. Materials and Methods: Direct contact test was used for the assessment. Three sets of sealers were mixed and placed on microtiter plate wells: One set was used within 20 min of recommended setting time while others were used after 24-h and 1-week. E. faecalis suspension was placed directly on the materials for $1 \mathrm{~h}$ and then transferred to another plate with fresh media. Nine wells of bacteria without the tested cements served as the positive control. One well of the tested cements without bacteria served as the negative control. Bacterial growth was evaluated by a temperature-controlled microplate spectrophotometer for 1-h intervals among $24 \mathrm{~h}$. Data were analyzed using Kruskal-Wallis test. Results: All tested materials showed less bacterial density than the control group. MTA, Biodentine, and Dycal showed significantly higher bacterial density than the control group in freshly mixed samples $(P<0.05)$. And MTA showed significantly higher antibacterial activity than Dycal $(P<0.05)$. In $24 \mathrm{~h}$, materials did not show any differences $(P>0.05)$. MTA and Biodentine samples showed significant differences than Dycal; MTA also showed higher antibacterial activity than control in 1-week samples $(P<0.05)$. Conclusion: While freshly mixed MTA showed the best antibacterial activity over time, Biodentine had shown similar antibacterial activity to MTA.

Key words: Antibacterial effect, bacteria, Biodentine, calcium hydroxide, calcium silicate, dental materials, direct contact test, Enterococcus faecalis, mineral trioxide aggregate, pulp capping

\section{INTRODUCTION}

Pulp damage might be resulted from the leftover microorganisms in dentine after the cavity preparation. This damage makes it necessary to use pulp-capping agents with antimicrobial activity underneath permanent restorations. The treatment can fail when the microorganisms in dentine, pulp, and periapical tissues persist and reproduce, especially in the long-term. ${ }^{[1]}$
Calcium hydroxide $(\mathrm{CH})$ and calcium silicate-based materials, and therapeutic agents are utilized widely within endodontics and dental traumatology in a wide range of treatment modalities. ${ }^{[2]}$ Vital pulp therapies consist of indirect and direct pulp-capping, partial (superficial) pulpotomy, and cervical pulpotomy. In general, only mechanically exposed healthy pulps of permanent teeth have been covered with a wound dressing consisting of $\mathrm{CH}^{\left[{ }^{[3]}\right.}$

\footnotetext{
How to cite this article: Koruyucu M, Topcuoglu N, Tuna EB, Ozel S, Gencay K, Kulekci G, Seymen F. An assessment of antibacterial activity of three pulp capping materials on Enterococcus faecalis by a direct contact test: An in vitro study. Eur J Dent 2015;9:240-5.

DOI: $10.4103 / 1305-7456.156837$
} 
A number of materials and drugs have been used as direct pulp capping agents, one of the most effective and popular one is $\mathrm{CH}_{0}{ }^{[4,5]}$ "Mineral trioxide aggregate" (MTA), known by its trade name, has been accepted quickly in dentistry since it was introduced in 1993 by Torabinejad who showed reparative dentin formation by odontoblast-like cells. ${ }^{[6-9]}$ Bismuth oxide served as a radiopacifier. They affirmed that the main ions in MTA were calcium and phosphorus tricalcium silicate, tricalcium aluminate, tricalcium oxide, and silicate oxide were the main components consisting of fine hydrophilic particles. Calcium and phosphorus were declared as the main ions in MTA. ${ }^{[9]}$ Their antibacterial traits are ascribed to its release of $\mathrm{CH}$ on surface hydrolysis of the calcium silicate components. ${ }^{[10]}$

A more recently used material as a dentin substitute, Biodentine $^{\mathrm{TM}}$ (Septodont, Saint Maur des Fosses, France) is a new fast-setting calcium silicate-based restorative material and it is suitable for direct restorative posterior filling, furcal perforation, retrograde filling, and pulp capping. ${ }^{[8]}$ On the biological level, its stimulation of odontoblast activity and reparative dentin, by induction of cell differentiation makes it perfectly biocompatible and capable of inducing the apposition of the reactionary dentin. On the biological level, its stimulation of odontoblast activity and reparative dentin, by induction of cell differentiation makes it perfectly biocompatible and capable of inducing the apposition of the reactionary dentin. Then, using a suitable carrier/gun it is applied to the pulpa exposure and left to set. ${ }^{[11]}$ The total preparation, placement, and setting approximately take 12 min. ${ }^{[12]}$

This investigation makes it clear that cultivable microorganisms usually infect the deeper layers of residual caries, in complete accordance with the findings of several studies. Thus, underneath the dental restorations; the usage of a pulp capping material with antimicrobial activity is vital. ${ }^{[13,14]}$

A known endodontic pathogen and a Gram-positive facultative anaerobic Coccus Enterococcus faecalis has often been regained from the root canals of teeth connected to postreatment diseases ${ }^{[15-17]}$ and persistent apical periodontitis. ${ }^{[18]}$ Its resistance to the intracanal medicament (e.g. calciumhydroxide) was also reported. ${ }^{[18]}$

The aim of this in vitro study was to evaluate antimicrobial activities of three different pulp-capping materials; Biodentine ${ }^{\mathrm{TM}}$, MTA Angelus, and Dycal, against $E$. faecalis, and their durability with time by direct contact test (DCT).

\section{MATERIALS AND METHODS}

The test materials evaluated in this study were MTA-Angelus (Angelus Ind. De Prod. Odontologicos S/A Brasil), Dycal (Dentsply Caulk, Canada) and Biodentine (Septodont RandD, France). All materials were prepared in strict compliance with the manufacturer's recommendation.

Direct contact test was used to determine the antibacterial activities of the materials. Three sets of each three material were mixed according to manufacturer's instructions and placed on 9 wells of 96-well microtiter plates: One set was used within 20 min after recommended setting time (freshly mixed samples), while others were used after 24-h and 1-week allowed to set at $37^{\circ} \mathrm{C}$ and $100 \%$ humidity. $10 \mu \mathrm{l}$ of bacterial suspension prepared with 24-h cultures of E. faecalis ATCC 29212 resuspended in fresh brain heart infusion (BHI; Difco Laboratories, Detroit, MI) broth (approximately $10^{6} \mathrm{CFU} / \mathrm{ml}$ ) was placed directly on ine of each material and incubated for $1 \mathrm{~h}$ in a humid atmosphere at $37^{\circ} \mathrm{C}$. BHI broth $(220 \mu \mathrm{l})$ was added to each of the wells and gently stirred for $2 \mathrm{~min} ; 10 \mu \mathrm{l}$ were then transferred to another plate, to an adjacent set of 6 wells containing fresh medium $(220 \mu \mathrm{l})$ and mixed. One well of the tested materials with sterilized $\mathrm{BHI}$ without bacteria served as the negative control, whereas nine uncoated wells without the tested cements served as the positive control. Identical bacterial inoculum was placed on the sidewall of the uncoated wells and processed as in the experimental wells.

The kinetics of the outgrowth in each well was monitored at $620 \mathrm{~nm}$ and recorded every hour using a microplate spectrophotometer (Uniquely Tecan Freedom EVO ${ }^{\circledR}$, Mannedorf, Switzerland) for 1-h intervals among $24 \mathrm{~h}$. Data were recorded in optical density (OD) units using Magellan program. Automixing prior to each reading ensured a homogeneous bacterial cell suspension. The values of the negative control wells were considered as the baseline and were then subtracted from the respective experimental sets and plotted as growth curves. The first set of data was recorded approximately $1 \mathrm{~h}$ after incubation.

All statistical analyses were performed using SPSS for Windows, version 10.0 (SPSS, Chicago, USA). The findings were analyzed statistically by Kruskal-Wallis test and Kruskal-Wallis post-hoc analysis. $P<0.05$ were considered significant. 


\section{RESULTS}

The results of the DCT for freshly mixed and aged cements in different antibacterial activity ratios are shown in Figures 1a, b, and c. All tested materials showed less bacterial density than the control group. The maximum antibacterial activity was observed respectively MTA, Biodentine, Dycal in freshly mixed samples and aged for $24 \mathrm{~h}$ [Figure $1 \mathrm{a}$ and b]. In 1-week samples, antibacterial activity of MTA and Biodentine was observed equal to each other and more than the control group and Dycal [Figure 1c].

The antibacterial effectiveness of Biodentine remained at the same standard levels in a week period although antibacterial effectiveness of MTA getting decreased and had the same levels with Biodentine. Immediate $(P=0.0020)$ and 1-week $(P=0.001)$ results were found significantly different association [Table 1].

According to post-hoc analysis; MTA showed significantly higher antibacterial activity than Dycal $(P<0.05)$. MTA, Biodentine, and Dycal showed significantly higher antibacterial activity than control in freshly mixed samples $(P<0.05)$. In $24 \mathrm{~h}$, materials did not show any differences $(P>0.05)$. MTA and Biodentine samples showed significant differences than Dycal; MTA also showed higher antibacterial activity than control in 1 -week samples $(P<0.05)$ [Table 2].

\section{DISCUSSION}

Historically, two different assays have been used to test the antimicrobial characteristics of the dental materials: The agar diffusion test (ADT) and the DCT. The DCT, as described by Weiss et al., is a quantitative and reproducible method designed to simulate the contact of the microorganism with the root repair materials in the root canal. ${ }^{[19]}$ DCT has many advantages over ADT. First, DCT allows for better control of confounding factors than the ADT. DCT was usually used to evaluate fresh sealers immediately after their manipulation while ADT was performed to analyze set sealers, 7 days after their mixture. Beside of this, in the ADT, the size of the inhibition zones from a certain substance depends on its diffusibility in the culture medium used. This fact is the one of the main disadvantages of this semi-quantitative method. ADT is able to demonstrate the activity of freshly mixed materials, which makes its inclusion interesting for comparative reasons with previous studies. ${ }^{[15,20]}$ The present study utilizes and proves DCT as an appropriate method of testing antimicrobial activity as in accordance with other studies. ${ }^{[21-24]}$

The antibacterial activity of dental cements has been intensively tested. $\mathrm{CH}$ is still considered the reference material for pulp capping, due to its antibacterial properties and its capacity to induce enzymatic

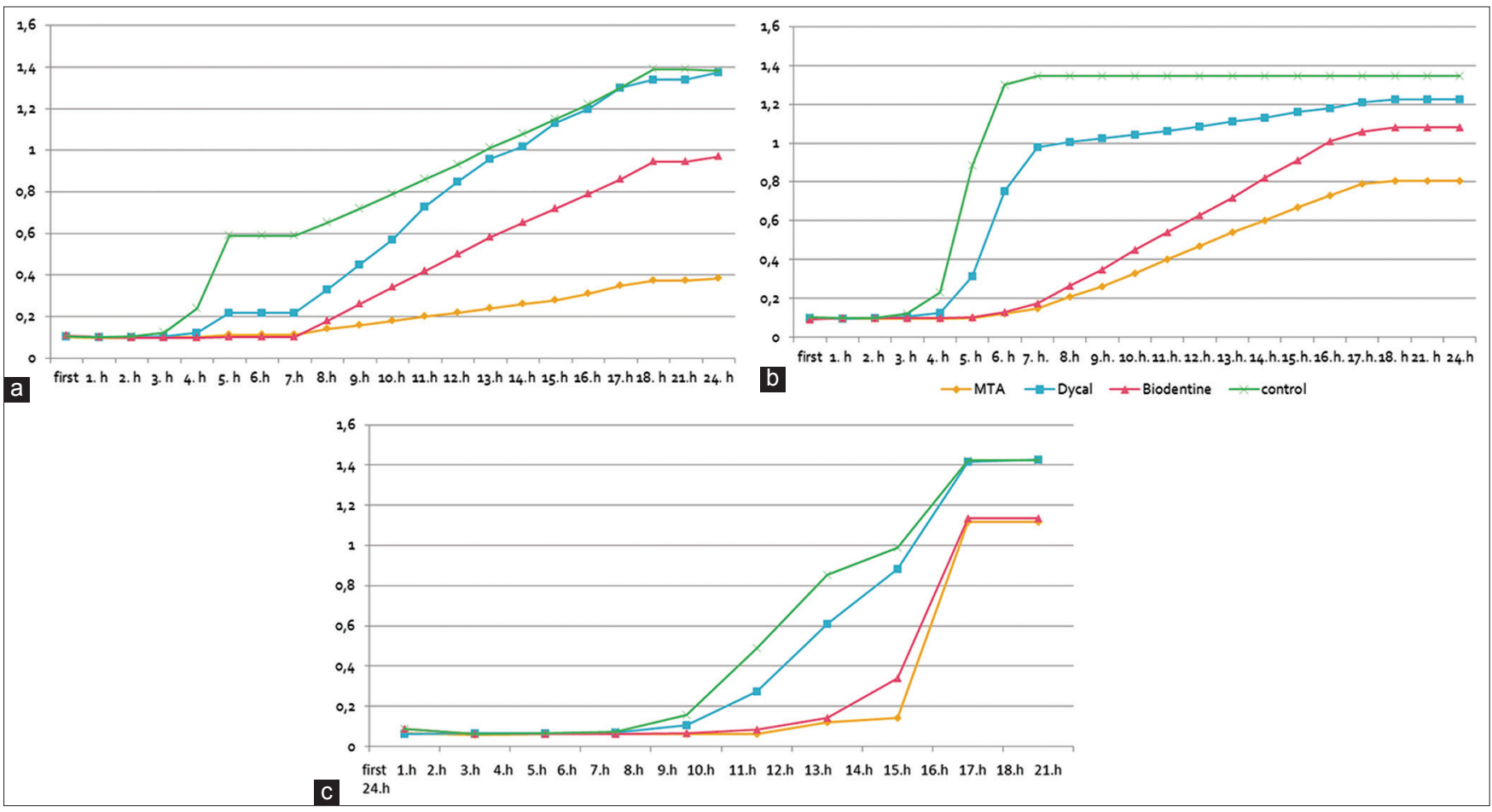

Figure 1: (a) Bacterial outgrowth of direct contact test (DCT) with freshly mixed materials. (b) Bacterial outgrowth of DCT with materials aged for $24 \mathrm{~h}$. (c) Bacterial outgrowth of DCT with materials aged for 1-week 
Koruyucu, et al.: Antibacterial activity of pulp capping materials

\begin{tabular}{|c|c|c|c|}
\hline \multirow[t]{2}{*}{ Materials } & \multicolumn{3}{|c|}{ Time (mean $\pm S D ;$ median (min-max)) } \\
\hline & Immediate & 24 hours & 1 week \\
\hline MTA & $0.29 \pm 0.54 ; 0.01(0.01-1.27)$ & $0.71 \pm 0.68 ; 1.23(0.00-1.37)$ & $0.95 \pm 0.35 ; 1.01(0.00-1.26)$ \\
\hline Dycal & $1.24 \pm 0.02 ; 1.24(1.22-1.27)$ & $1.13 \pm 0.42 ; 1.27(0.00-1.30)$ & $1.23 \pm 0.43 ; 1.37(0.01-1.39)$ \\
\hline Biodentine & $0.87 \pm 0.65 ; 1.24(0.00-1.47)$ & $0.98 \pm 0.55 ; 1.25(0.00-1.29)$ & $0.87 \pm 0.56 ; 1.28(0.00-1.33)$ \\
\hline Control & $1.28 \pm 0.02 ; 1.28(1.26-1.31)$ & $1.25 \pm 0.01 ; 1.26(1.23-1.26)$ & $1.29 \pm 0.41 ; 1.36(0.08-1.37)$ \\
\hline$P$ values & $0.0020^{*}$ & 0.3585 & $0.001^{*}$ \\
\hline
\end{tabular}

\begin{tabular}{|c|c|c|c|}
\hline Materials comparisons & Immediate & 24 hours & 1 week \\
\hline MTA-Biodentine & $p>0.05$ & $p>0.05$ & $p>0.05$ \\
\hline MTA-Dycal & $p<0.05^{*}$ & $p>0.05$ & $p \leq 0.05^{*}$ \\
\hline Biodentine-Dycal & $p>0.05$ & $p>0.05$ & $p<0.05^{*}$ \\
\hline MTA-Kontrol & $p<0.05^{*}$ & $p>0.05$ & $p<0.05^{*}$ \\
\hline Biodentine-Kontrol & $p<0.05^{*}$ & $p>0.05$ & $p>0.05$ \\
\hline Dycal-Kontrol & $p<0.05^{*}$ & $p>0.05$ & $p>0.05$ \\
\hline
\end{tabular}

reactions leading to the formation of a dentine bridge. Antibacterial activity of $\mathrm{CH}$-based materials depends on the ionization that releases hydroxyl ions causing an increase in $\mathrm{pH}$. Cellular membrane enzymes of the microorganism might be reversibly or irreversibly inactivated by a $\mathrm{pH} \cdot{ }^{[23]}$ Furthermore, long-term clinical studies have reported varying success rates, due to the persistence of an inflammatory process and cytotoxic effects. In recent years, MTA has been proposed as a suitable material for pulp capping, on the basis of its biological properties. MTA causes less inflammation than $\mathrm{CH}$ and stimulates the differentiation and proliferation of pulp cells, thereby facilitating the formation of a more structured mineralized barrier. On the basis of these qualities, MTA is currently considered the "gold standard" material, despite two major disadvantages of its use: The long time required for setting $(2.75 \mathrm{~h})$ and the need for moisture during setting. ${ }^{[11,25,26]} \mathrm{CH}$ showed significantly better antibacterial effect than MTA in Asgary et al. study. ${ }^{[5]}$ The results of the current study showed a difference with this study.

Today, the new dental materials based on tricalcium silicate have been developed. These materials are synthesized in the laboratory from high purity raw materials, unlike the Portland cement in MTA. One such formulation is Biodentine $^{\mathrm{TM}}$ (Septodont), which was developed as dentin replacement material. This material is also used to restorate the deep and large coronal carious lesions, to restorate deep cervical and radicular lesions, to do pulp capping and pulpotomy, to repair root perforations, furcation perforations; to repair root perforations, furcation perforations; to perforate internal resorptions, external resorption, apexification, and to fill root-end in endodontic surgery. $[27,28]$

The principal advantages of Biodentine over MTA are its greater viscosity and its shorter setting time (12 min). These properties make Biodentine both a substitution material for dentine and a suitable material for use in pulp-capping. ${ }^{[11,25,26]}$ Biodentine $^{\mathrm{TM}}$ has an advantage over such materials, which arises from the fact that besides its biocompatibility, the strong suggestion of its mechanical and physical properties that in the future it will be used not only as a pulp capping agent but as a dentin substitute. ${ }^{[28,29]}$

In a study performed by Shayegan et al., they assessed the pulpal response of primary pig teeth against Biodentine when used as a pulp capping as well as a pulpotomy material. The authors commented that Biodentine has bioactive properties, encourages hard tissue regeneration, and did not show pulp inflammation response. It has also great sealing properties; there is no risk of microleakage, which may cause the pulp to become infected or necrotic. Another important comment was that the hard tissue formation due to $\mathrm{CH}$ was rather a defense response of the pulp against the irritant nature of the material whereas calcium silicate-based materials are compatible with the cell recruitment. ${ }^{[30]}$

Studies report that pulp response after direct capping is linked to bacterial microleakage. Microbes interfere with the pulpal response to capping materials. It was noted that bacteria stimulate pulpal inflammatory activity and reduce the area of dentin bridge formation irrespective of the material used for pulp capping. Many studies indicate that it is not an agent's potential bioactivity but its capacity to protect the pulp from bacterial exposure that plays a role in pulpal survival after an oral exposure. ${ }^{[1,8]}$ Nowicka et al. presents comprehensive data on the bridge and pulpal inflammation with a similar outcome of pulp capping with Biodentine and MTA. Therefore, since 
the two capping techniques (Biodentine and MTA) as a direct pulp capping in human teeth does not have any different outcome in the pulp-dentin complex response, the null hypothesis suggesting that can be accepted. $^{[8]}$

Even though aerobic and facultative bacteria are not mostly the major constituents of primary infections, in the selection of test bacteria for this study they have been observed more frequently in the failed treatment cases. ${ }^{[5,31]}$ In the research whose goal is to calculate the antimicrobial properties of endodontic materials, E. faecalis, a Gram-positive facultative anaerobe, is mostly used. E. faecalis has an ability to survive the effects of conventional root canal therapy due to its many virulence factors. Moreover, it is capable of invading dentine tubules and binding to collagen. ${ }^{[20]}$

In the study of Zhang et al., the antibacterial effect of MTA and BA at low concentrations was investigated with their suspensions, and they showed similar bacterial killing and wholly destroyed all bacteria in $1 \mathrm{~h}$. They found that gray MTA showed greater E. faecalis growth inhibition than white MTA. Another study reported no antimicrobial activity of MTA against E. faecalis in ADT and reported that MTA demonstrated antimicrobial activity against E. faecalis, Micrococcus luteus, Staphylococcus aureus, Staphylococcus epidermidis, Pseudomonas aeruginosa, and Candida albicansbut not against Escherichia coli with double-layered diffusion method. However, it is not meaningful to make comparisons among studies with different methodologies. ${ }^{[31]}$

Previous studies have shown conflicting results regarding the antibacterial activity of pulp capping materials. For instance, while in some studies MTA was effective against microorganisms including E. faecalis, ${ }^{[2,31]}$ in the others its antimicrobial activity was limited. ${ }^{[24,31]}$ Concentrations and the type of preparation determine the antibacterial efficacy of MTA. ${ }^{[14,24]}$

Using ADT Torabinejad et al. examined the antibacterial effect of some root end filling materials and concluded that MTA had no antibacterial activity against E. faecalis, S. aureus and Bacillus subtilis and there was not any effect on the strict anaerobic bacteria. ${ }^{[9]}$ MTA on S. aureus, E. faecalis, and B. subtilis gave similar results as those using Portland There were no meaningful differences between the diffusion zone of MTA and Portland cement. $\mathrm{CH}$ had a superior antimicrobial activity overall microorganisms studied, which were MTA, Portland cement, Sealapex, and Dycal. ${ }^{[5]}$
Perard et al. reported that when there are biomaterials derived from Portland cement, the viability of cells cultured in vitro decreases. Many possible reasons of this have been suggested. The bactericidal effect of MTA may result from the release of $\mathrm{CH}$, and this may cause the denaturation of proteins in the medium and $\mathrm{pH}$ fluctuations. ${ }^{[25]}$

\section{CONCLUSION}

Clinical criterion has been accepted inadequate for the long-term prognosis because critical evaluation of the results of pulp-capping materials can only be made with a wide range of clinical and histological studies. In conclusion, while MTA was better antibacterial in freshly mixed samples over time MTA and Biodentine showed better antibacterial activity.

\section{REFERENCES}

1. Neelakantan P, Rao CV, Indramohan J. Bacteriology of deep carious lesions underneath amalgam restorations with different pulp-capping materials - An in vivo analysis. J Appl Oral Sci 2012;20:139-45.

2. Mohammadi Z, Dummer PM. Properties and applications of calcium hydroxide in endodontics and dental traumatology. Int Endod J 2011;44:697-730.

3. Schuurs AH, Gruythuysen RJ, Wesselink PR. Pulp capping with adhesive resin-based composite vs. calcium hydroxide: A review. Endod Dent Traumatol 2000;16:240-50.

4. Farhad A, Mohammadi Z. Calcium hydroxide: A review. Int Dent J 2005;55:293-301.

5. Asgary S, Akbari Kamrani F, Taheri S. Evaluation of antimicrobial effect of MTA, calcium hydroxide, and CEM cement. Iran Endod J 2007;2:105-9.

6. Min KS, Park HJ, Lee SK, Park SH, Hong CU, Kim HW, et al. Effect of mineral trioxide aggregate on dentin bridge formation and expression of dentin sialoprotein and heme oxygenase- 1 in human dental pulp. J Endod 2008;34:666-70.

7. Accorinte Mde L, Holland R, Reis A, Bortoluzzi MC, Murata SS, Dezan E Jr, et al. Evaluation of mineral trioxide aggregate and calcium hydroxide cement as pulp-capping agents in human teeth. J Endod 2008;34:1-6.

8. Nowicka A, Lipski M, Parafiniuk M, Sporniak-Tutak K, Lichota D, Kosierkiewicz A, et al. Response of human dental pulp capped with biodentine and mineral trioxide aggregate. J Endod 2013;39:743-7.

9. Torabinejad M, Hong CU, McDonald F, Pitt Ford TR. Physical and chemical properties of a new root-end filling material. J Endod 1995;21:349-53.

10. Parirokh M, Torabinejad M. Mineral trioxide aggregate: A comprehensive literature review - Part I: Chemical, physical, and antibacterial properties. J Endod 2010;36:16-27.

11. Laurent $P, C$ Camps J, De Méo M, Déjou J, About I. Induction of specific cell responses to a $\mathrm{Ca}(3) \mathrm{SiO}$ (5)-based posterior restorative material. Dent Mater 2008;24:1486-94.

12. Barnes JJ, Patel S. Contemporary endodontics - Part 1. Br Dent J 2011;211:463-8.

13. Byun R, Nadkarni MA, Chhour KL, Martin FE, Jacques NA, Hunter N. Quantitative analysis of diverse Lactobacillus species present in advanced dental caries. J Clin Microbiol 2004;42:3128-36.

14. Ribeiro CS, Kuteken FA, Hirata Júnior R, Scelza MF. Comparative evaluation of antimicrobial action of MTA, calcium hydroxide and Portland cement. J Appl Oral Sci 2006;14:330-3.

15. Porteneier I, Waltimo TM, Haapasalo M. Enterococcus faecalis the root canal survivor and 'star' in post-treatment disease. Endod Topics 2003;6:135-59.

16. Sundqvist G, Figdor D, Persson S, Sjögren U. Microbiologic analysis 
of teeth with failed endodontic treatment and the outcome of conservative re-treatment. Oral Surg Oral Med Oral Pathol Oral Radiol Endod 1998;85:86-93.

17. Hancock HH $3^{\text {rd }}$, Sigurdsson A, Trope M, Moiseiwitsch J. Bacteria isolated after unsuccessful endodontic treatment in a North American population. Oral Surg Oral Med Oral Pathol Oral Radiol Endod 2001;91:579-86.

18. Haapasalo HK, Sirén EK, Waltimo TM, Ørstavik D, Haapasalo MP. Inactivation of local root canal medicaments by dentine: An in vitro study. Int Endod J 2000;33:126-31.

19. Weiss EI, Shalhav M, Fuss Z. Assessment of antibacterial activity of endodontic sealers by a direct contact test. Endod Dent Traumatol 1996;12:179-84.

20. Morgental RD, Vier-Pelisser FV, Oliveira SD, Antunes FC, Cogo DM, Kopper PM. Antibacterial activity of two MTA-based root canal sealers. Int Endod J 2011;44:1128-33.

21. Anumula L, Kumar S, Kumar VS, Sekhar C, Krishna M, Pathapati RM, et al. An assessment of antibacterial activity of four endodontic sealers on Enterococcus faecalis by a direct contact test: An in vitro study. ISRN Dent 2012;2012:989781.

22. Lewinstein I, Matalon S, Slutzkey S, Weiss EI. Antibacterial properties of aged dental cements evaluated by direct-contact and agar diffusion tests. J Prosthet Dent 2005;93:364-71.

23. Eldeniz AU, Erdemir A, Hadimli HH, Belli S, Erganis O. Assessment of antibacterial activity of EndoREZ. Oral Surg Oral Med Oral Pathol Oral Radiol Endod 2006;102:119-26.

24. Lovato KF, Sedgley CM. Antibacterial activity of endosequence root repair material and proroot MTA against clinical isolates of Enterococcus faecalis. J Endod 2011;37:1542-6.

25. Pérard M, Le Clerc J, Watrin T, Meary F, Pérez F, Tricot-Doleux S, et al.
Spheroid model study comparing the biocompatibility of Biodentine and MTA. J Mater Sci Mater Med 2013;24:1527-34.

26. Tran XV, Gorin C, Willig C, Baroukh B, Pellat B, Decup F, et al. Effect of a calcium-silicate-based restorative cement on pulp repair. J Dent Res 2012;91:1166-71.

27. Camilleri J, Sorrentino F, Damidot D. Investigation of the hydration and bioactivity of radiopacified tricalcium silicate cement, Biodentine and MTA Angelus. Dent Mater 2013;29:580-93.

28. Camilleri J. Investigation of Biodentine as dentine replacement material. J Dent 2013;41:600-10.

29. About I, Camps J, Burger AS, Mitsiadis TA, Butler W, Franquin JC. The effects of bonding agents on the differentiation in vitro of human pulp cells into odontoblasts. Dent Mater 2005;21:156-63.

30. Shayegan A, Jurysta C, Atash R, Petein M, Abbeele AV. Biodentine used as a pulp-capping agent in primary pig teeth. Pediatr Dent 2012;34:e202-8

31. Zhang H, Pappen FG, Haapasalo M. Dentin enhances the antibacterial effect of mineral trioxide aggregate and bioaggregate. J Endod 2009;35:221-4.

\begin{tabular}{|l|l|}
\hline \multicolumn{2}{|c|}{ Access this article online } \\
\hline Quick Response Code: & Website: \\
\hline & www.eurjdent.com \\
\hline
\end{tabular}

